\title{
The Hyperglycaemia after Potassium Cyanide in Rabbits, Splanchnicotomized or Suprarenalectomized.
}

\author{
$\mathrm{By}$ \\ FUMIO OHMI. \\ (近江交男) \\ (From the Physiological Laboratory of Prof. Y. Satake, \\ Tohoku Imperial University, Sendai.)
}

Nearly all the observers have agreed in eliciting hyperglycaemia by giving hydrocyanic acid or its salts to rabbits or dogs. ${ }^{1,2,4,5,6)}$ These were administered intravenously ${ }^{2)}$ or subcutaneously. Only Yano and $\mathrm{Kirita}{ }^{33}$ were not only unable to detect an increase in the blood sugar concentration in rabbits by letting them inhale hydrocyanic gas, but also on the contrary they detected a remarkable decrease as to one third of the initial; the hypoglycaemia did not appear when the gas was given to rabbits, doubly splanchnicotomized. The rabbits, operated on similarly, were also used by $\mathrm{Kudo}_{0}^{6}$; according to him hydrocyanic acid induces the first transitory hyperglycaemia and the second one, and the splanchnicotomy diminishes the first increase and wholly abolishes the second. Kawamura ${ }^{4)}$ is apt also to assume that the hyperglycaemia is divided in two by interpolating the hypoglycaemic spell.

In order to know whether or not cyanide hyperglycaemia is of the cental origin and whether or not the suprarenal glands are dispensable in causing the hyperglycaemia by giving cyanide, the present investigations were performed on rabbits, normal, splanchnicotomized and suprarenalectomized as well.

1) Zillessen, Ho ppe-Seylers Zeitschr., 1891, 15, 387 (Cyan acid solution per os or subcutaneously, slight hyperglycaemia, no glycosuria in rabbits, but slight glycosuria in dogs).

2) Tatum and Atkinson, Jour. of Biol. Chem., 1922, 54, 331.

3) Yano and Kirita, Chugai Iji Shimpo, 1926, 810.

4) K a w a mura, Kyoto-Ikadaigaku-Zasshi, 1928, 2, Part B, 155 (German).

5) Od a, Nihon Naibumpitsu Gakkai Zasshi, 1929, 5, 393.

6) Kudo, Manshu Igakkai Zasshi, 1930, 13, 413. 
Mostly male rabbits were used, but in a few cases female, but non-pregnant ones were experimented on. All the techniques in feeding and treating the animals, cutting the splanchnic nerves and removing the suprarenals and determining the blood sugar content, etc., are given in my previous paper. ${ }^{\text {? }}$

$1 \% \mathrm{KCN}$ (Merck) solution, prepared freshly every time, was injected under the skin of rabbits, always in a dose of $2.5 \mathrm{mgrms}$. KCN per kilo of body weight.

At the end of the paper are three tables compiled from the data in three kinds of animals, normal, suprarenalectomized and splanchnicotomized.

Normal liabbits: The data from 7 male, normal rabbits may be mentioned firstly.

ExaMPLE I.

Normal rabbit, 2. 3 .

(N. auricularis magnus and the cervical sympathetic nerve were cut on the left side)

10. IV. 1931. of 1.95 kilos.

\begin{tabular}{|c|c|c|c|c|c|}
\hline Time & $\begin{array}{c}\text { Blood } \\
\text { sugar } \\
(\%)\end{array}$ & $\begin{array}{c}\text { Frequency } \\
\text { of respi- } \\
\text { ration } \\
\text { (per min.) }\end{array}$ & $\begin{array}{c}\text { Body tem- } \\
\text { perature } \\
\left({ }^{\circ} \mathrm{C} .\right)\end{array}$ & $\begin{array}{c}\text { Room tem- } \\
\text { perature } \\
\left({ }^{\circ} \mathrm{C} .\right)\end{array}$ & Remarks \\
\hline 11:00 a.m. & 0.098 & 90 & 38.7 & 16.5 & \\
\hline $11: 15$ & \multicolumn{5}{|c|}{$\begin{array}{l}\text { Injected } 2.5 \text { mgrms. potassium cyanide } \\
\text { per kilo body weight subcutaneously. }\end{array}$} \\
\hline $11: 27$ & 0.156 & 150 & 38.6 & 16.5 & \multirow{15}{*}{$\begin{array}{l}3 \text { minutes after injection } \\
\text { the respiration accelerat- } \\
\text { ed gradually, fulther two } \\
\text { minutes later severe con- } \\
\text { vulsions set in, then the } \\
\text { animal fell on its side, con- } \\
\text { vulsions occurred from } \\
\text { time to time. Cornea re- } \\
\text { flex disappeared, respira- } \\
\text { tion very deep. Thirty } \\
\text { minutes after injection the } \\
\text { animal get up scarcely, re- } \\
\text { spiration } 108 \text { a minute, } 5 \\
\text { minutes later the general } \\
\text { behavior showed a ten- } \\
\text { dency of recovery, respira- } \\
\text { tion } 120 \text {; } 10 \text { minutes fur- } \\
\text { ther later the recovery be- } \\
\text { came somewhat evident, } \\
\text { respiration } 180 \text {. } 60 \text { mi- } \\
\text { nutes after injection the } \\
\text { animal quiet, apparently } \\
\text { normal. }\end{array}$} \\
\hline $11: 34$ & 0.187 & 104 & & 17 & \\
\hline $11: 40$ & 0.206 & 72 & 38.5 & & \\
\hline $11: 45$ & 0.225 & 100 & & & \\
\hline $11: 50$ & 0.229 & 120 & 88.3 & 17.5 & \\
\hline $12: 00 \mathrm{~m}$ & 0.216 & 180 & & & \\
\hline $12: 15$ p.m. & 0.208 & 108 & & 17.5 & \\
\hline $12: 45$ & 0.203 & 66 & 38.5 & & \\
\hline $1: 15$ & 0.181 & 66 & & 18 & \\
\hline $1: 45$ & 0.163 & 66 & 38.6 & & \\
\hline $2: 15$ & 0.134 & 66 & & 18 & \\
\hline $2: 45$ & 0.105 & 72 & 38.6 & & \\
\hline $3: 15$ & 0.102 & 60 & & & \\
\hline $3: 45$ & 0.095 & 66 & 38.7 & 18.5 & \\
\hline $4: 15$ & 0.096 & 72 & 38.8 & & \\
\hline
\end{tabular}

7) $0 \mathrm{~h} \mathrm{mi}$, Tohoku Jour. of Exp. Med., 1933, 20, 498. 
On receiving the hypodermical injection the breathing became generally largely accelerated for a while, and then deep. 3 to 5 minutes after the injection all the rabbits, except No. 3 , became uneasy, the equilibrium of the body seriously disturbed, lay down and convulsions of various degrees set in. When the seizures were very violent, the respiration stopped though quite transiently. The heart beat very weakly. When convulsions no more occurred, the body then became flaccid, the reflexes disappeared, the paralytic stage thus began. The Cheyne-Stokes' type of respiration was very often observed just before and during the paralytic stage. When the attack of convulsions was manifested repeatedly, as in Nos. $1,2,4 \& 5$, the paralytic stage also lasted long; Rabbit No. 5 was still paralytic at the end of 5 hours of poisoning.

The anal temperature descended a little on receiving cyanide. A decrease of 0.2 to $0.6^{\circ}$ was the maximum, which was estimated a half hour after the injection to 3 hours thereafter. Afterwards the body temperature showed a tendency to recover or further to exceed finally the initial though very slightly.

The blood sugar content of 7 normal rabbits without exception increased on injecting cyanide. The maximum as $0.137 \%$ to $0.229 \%$, mean of 7 cases $0.185 \%$ was reached about 30 minutes to 100 minutes after the injection, and then the sugar level descended gradually. In the observation extending for 4 to 5 hours after the injection no hypoglycaemic stage was found, although in some cases as Nos. 1, 2, 5, 6 a little smaller content compared with the initial was found, as from $0.098 \%$ to $0.09 \%$ in No. 1 . Notwithstanding the sugar estimations were done every 5 minutes during 30 minutes after the injection, every 10 minutes during next thirty minutes and then every thirty minutes during the rest of the experiment, I have not been able to see a case of hyperglycaemia with two summits in the whole course of cyanide poisoning, as some experimentalists have written.

In two cases out of 7 , the blood sugar content 5 minutes after the injection was definitely smaller than the initial, but the inferiority was too small to speak of the appearance of hypoglycaemia; and the next collected 5 minutes later or the third sample collected 10 minutes later was identical with the initial. It miglut be difficult or unjustifiable to take this quite small and transitory diminution in the blood sugar as a small copy of the hypoglycaemia detected by Yano and Kirita. The latter was of remarkable degree, as about $0.035 \%$ in two cases and $0.052 \%$ and $0.050 \%$ in the other two. They failed further to find any occurrence of hyperglycaemia. Their findings are more remarkable in that they were able to see a definite hyperglycaemia in rabbits by letting them breathe $\mathrm{CO}$ gas, the common outcome.

While Kawamura and $\mathrm{Ku}$ do obtained only a small degree of hyperglycaemia and sometimes rather inconstant outcome by giving similar doses as the present, the hyperglycaemia occurred in the present rabbits in a moderately great magnitude always, as Tatum and Atkinson. 
The peak of hyperglycaemia did not coincide in the time relation with the maximum acceleration in the respiration frequency and the minimum of the anal temperature. The peak of hyperglycaemia was determined when the respiration was still accelerated, as in Nos. $1,2,3 \& 6$, but in the three others it was detected after the respiration rhythm had already become much less than the initial. The minimum anal temperature was noted sometimes earlier, sometimes much later than the peak of hyperglycaemia; in two cases, No. 2, given as Example, and No. 6, they coincided.

Doubly Suprarcnalectomized Rabbits: All male; 35 to 72 days were allowed to elapse from the second decapsulation to the cyanide injection. The same dosage of potassium cyanide was resorted to. The initial blood sugar was 0.091 to $0.104 \%$ in 4 so operated rabbits, not a whit different from the values found in normal animals. Similar poisoning symptoms were elicited in these animals as in the normal ones, as shown in a protocol reproduced here. In Rabbits Nos. 8 \& 10 the Cheyne-Stokes' type of respiration was also observed.

\section{Example III.}

Doubly suprarenalectomized rabbit.

20. II. 1931. 1.57 kilos. R suprarenalectomy.

4. IV. $\quad 1.95$ kilos. I suprarenalectomy.

6. IV. $R \mathrm{n}$. auricularis magnus and the cervical sympathetic nerve cut.

\begin{tabular}{|c|c|c|c|c|c|}
\hline Time & $\begin{array}{l}\text { Blood } \\
\text { sugar } \\
(\%)\end{array}$ & $\begin{array}{c}\text { Frequency } \\
\text { of respi- } \\
\text { ration } \\
\text { (per min.) }\end{array}$ & $\begin{array}{c}\text { Body tem- } \\
\text { perature } \\
\left({ }^{\circ} \mathrm{C} .\right)\end{array}$ & $\begin{array}{c}\text { Room tem- } \\
\text { perature } \\
\left({ }^{\circ} \mathrm{C} .\right)\end{array}$ & Remarks \\
\hline $\begin{array}{l}\text { 2:00 p.m. } \\
2: 10\end{array}$ & $\begin{array}{l}0.096 \\
\text { Inject } \\
\text { per }\end{array}$ & $\begin{array}{l}112 \\
2.5 \text { mgl'ms } \\
\text { body weis }\end{array}$ & $\begin{array}{l}38.9 \\
\text { potassium } \\
\text { pht subeuta }\end{array}$ & $\begin{array}{r}18.5 \\
\text { cyanide } \\
\text { neously. }\end{array}$ & \\
\hline $2: 15$ & 0.098 & 168 & 38.7 & 18.5 & Violent convulsions occur- \\
\hline $\begin{array}{l}2: 20 \\
2: 25\end{array}$ & $\begin{array}{l}0.115 \\
0.166\end{array}$ & 78 & 38.5 & & red 5 minutes after injec- \\
\hline $2: 30$ & $\begin{array}{l}0.166 \\
0.173\end{array}$ & $\begin{array}{r}66 \\
124\end{array}$ & $\begin{array}{l}38.4 \\
38.4\end{array}$ & 18.5 & $\begin{array}{l}\text { tion and during next ten } \\
\text { minutes the animal was }\end{array}$ \\
\hline $2: 35$ & 0.175 & 146 & 38.6 & 19 & attacked by severe ones, \\
\hline $\begin{array}{l}2: 40 \\
2: 50\end{array}$ & $\begin{array}{l}0.176 \\
0.167\end{array}$ & $\begin{array}{l}150 \\
138\end{array}$ & 38.6 & & and the respiration deep. \\
\hline $3: 00$ & 0.162 & 134 & $\begin{array}{l}38.6 \\
38.7\end{array}$ & 19 & $\begin{array}{l}20 \text { minutes after injection } \\
\text { breathing frequent, and }\end{array}$ \\
\hline $3: 10$ & 0.140 & 130 & 38.8 & & the animal lay down. 45 \\
\hline $3: 30$ & 0.133 & 132 & 38.9 & 19 & minutes after injection \\
\hline $\begin{array}{l}4: 00 \\
4: 30\end{array}$ & $\begin{array}{l}0.096 \\
0.095\end{array}$ & $\begin{array}{l}118 \\
124\end{array}$ & 38.9 & 18 & the general behavior indi- \\
\hline 5:00 & 0.093 & $\begin{array}{l}124 \\
128\end{array}$ & $\begin{array}{l}39.1 \\
39.1\end{array}$ & 18 & $\begin{array}{l}\text { cates a tendency to re- } \\
\text { cover, and } 15 \text { minutes }\end{array}$ \\
\hline $6: 00$ & 0.095 & 126 & 39.0 & 18 & $\begin{array}{l}\text { later it appeared wholly } \\
\text { recovered. }\end{array}$ \\
\hline
\end{tabular}

The blood sugar concentration increased definitely on cyanide injection without one exceptional case. The peak was of such values as 0.142 to $0.176 \%$, a little inferior to that in the normal rabbits, and it was reached on an average a little earlier too. But if two cases, 
Nos. $5 \& 7$, of normal rabbits which betrayed somewhat large degree of hyperglycaemia as $0.245 \%$ and $0.208 \%$ respectively, be left out of consideration, the time needed for reaching the peak of hyperglycaemia well coincides in both sets of animals, normal and doubly suprarenalectomized. The time with which the descending limb of hyperglycaemia achieved the initial value of blood sugar, was only a little shorter on an average in this set of experiments than in the normal rabbits.

Only in a single case, namely in No. 10 , the blood taken 5 minutes after the injection contained a little smaller amount of sugar compared with the initial. $0.091 \%$ and $0.086 \%$ were such figures. In the descending limb of hyperglycaemia no special depression was obtained, that is the hyperglycaemia disappeared gradually and smoothly. Only a small diminution in the blood sugar concentration from the initial appeared in the later period of experimentation extending for 4-5 hours, but the absolute amount was never smaller than $0.09 \%$.

The time relation between the peak of hyperglycaemia, the maximum frequency of respiration and the minimum anal temperature was similar with the set of normal rabbits.

Doubly splanchnicotomized Rabbits: The outcome of this set of rabbits largely differed from the other two. At least two weeks were allowed between the splanchnicotomy and the cyanide experiment, as shown in Table III.

11 rabbits, involving two females, were experimented on. No alteration is necessary in the above description of the general intoxication symptoms in the normal rabbits.

The initial blood sugar level was $0.088 \%$ to $0.096 \%$, mean $0.092 \%$. On receiving cyanide in the same dose as the other groups of rabbits, the blood sugar content fluctuated very slightly contrary to the other groups; in 8 of 11 cases the sugar content increased to from $0.105 \%$ to $0.123 \%$, very small, though unmistakable, commonly 15 minutes to 1 hour after the injection, seldom 2.5 hours and 3.5 hours thereafter. The latter, Nos. 15 and 19 , may be taken as the second hyperglycaemic period of Kawamura and $K u d o$, for the time when it appeared checks with that given by them, and in the earlier stage the rabbits showed quite transitorily a small increase in the blood sugar. But we have found such cases only exceptionally, so that we hesitate to say that their findings are an exaggeration of those detected in these two rabbits. In the rest, that is Nos. 13,17 and 22, no increase was witnessed at all in the blood sugar concentration.

The hyperglycaemia in 6 rabbits, though far small in intensity, can be taken as a small manifestation of the hyperglycaemia due to cyanide by judging from the time course of the level variation. 
EXAMPLE III.

Doubly splanchnicotomized rabbit.

(25. III. 1931. 1.5 kilos. Double splanchnicotomy \& denervation of $R$ ear.)

21. IV. 1931. Rabbit of $1.51 \mathrm{kilos}$.

\begin{tabular}{|c|c|c|c|c|c|}
\hline Time & $\begin{array}{c}\text { Blood } \\
\text { sugar } \\
(\%)\end{array}$ & $\begin{array}{c}\text { Frequency } \\
\text { of respi- } \\
\text { ration } \\
\text { (per min.) }\end{array}$ & $\begin{array}{c}\text { Body tem- } \\
\text { perature } \\
\left({ }^{\circ} \mathrm{C} .\right)\end{array}$ & $\begin{array}{c}\text { Room tem- } \\
\text { perature } \\
\left({ }^{\circ} \mathrm{C} .\right)\end{array}$ & Remarks \\
\hline 2:50 p.m. & 0.091 & 118 & 38.9 & 16.5 & \\
\hline $3: 00$ & \multicolumn{5}{|c|}{$\begin{array}{l}\text { Injected } 2.5 \mathrm{mgl} \text { ms potassium cyanide } \\
\text { per kilo body weight subcutaneously. }\end{array}$} \\
\hline $3: 05$ & 0.098 & 146 & 38.7 & 16.5 & 5 minutes after injection \\
\hline $3: 10$ & 0.097 & & & & the animal uneasy, respi- \\
\hline $3: 15$ & 0.100 & 150 & 38.5 & 17 & ration remarkably accele- \\
\hline $3: 20$ & 0.107 & & & & rated. 10 minutes later \\
\hline $3: 30$ & 0.123 & 126 & 38.6 & 17.5 & slight convulsions, apa- \\
\hline $3: 40$ & 0.123 & & & & thetic, and lay down. 60 \\
\hline $3: 50$ & 0.119 & 92 & 38.4 & 17.5 & minutes after injection \\
\hline 4:00 & 0.117 & & & & some sign of recovery. \\
\hline $4: 15$ & 0.120 & 88 & 38.5 & 17 & $3: 20$ apparently wholly \\
\hline $4: 30$ & 0.118 & & & & normal. \\
\hline $5: 00$ & 0.102 & 102 & 38.7 & 16.5 & \\
\hline $5: 30$ & 0.093 & & & & \\
\hline $6: 00$ & 0.092 & 106 & 38.9 & 16 & \\
\hline $6: 30$ & 0.090 & & & & \\
\hline $7: 00$ & 0.090 & 108 & 39.1 & 16 & \\
\hline
\end{tabular}

This time a remarkable decrease was discovered in the blood sugar in a few cases. Rabbit 13 developed the hypoglycaemic spell soon after the poisoning, and so small a content as $0.052 \%$ was measured 20 minutes after the injection, and this spell lasted for 4.5 hours, but at the end of the experiment, that is 5 hours after the injection just the initial value was again noted. A hypoglycaemia as $0.074 \%$ occurred in Rabbit 17, and the hypoglycaemic period lasted also long in this case. Somewhat low concentration of the blood sugar was also measured in Rabbit $14(0.08 \%)$, Rabbit $21(0.084 \%)$ and Rabbit 22 $(0.078 \%)$ only, in the remainder the content lower than the initial was never discovered through the whole routine of experiment covering $4-5$ hours. The extensive hypoglycaemia visible in Rabbits 13 and 17 was noted in the paper of Yano and Kirita, but they saw such a phenomenon in normal rabbits, and when the splanchnic nerves were interfered with it disappeared totally, a rather diametrically opposite finding.

In order to show at a glance the effect of the double suprarenalectomy and of the double splanchnicotomy upon the carbohydrate metabolism disturbance due to the cyanide poisoning, the following chart is constructed. Solid circles connected with solid lines indicate 


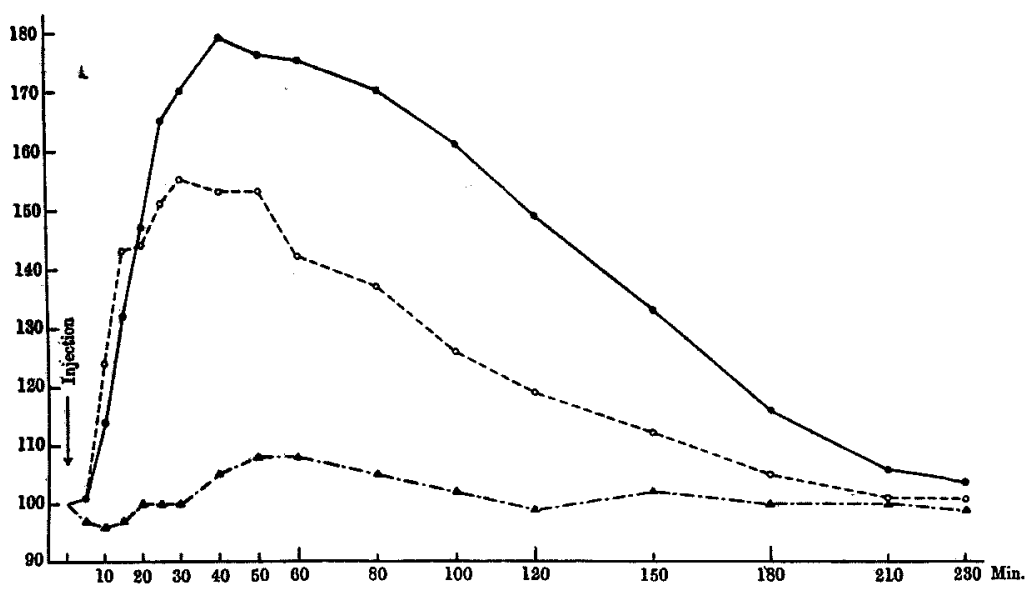

The initial values of blood sugar content are taken here as 100 . Solid circles with solid lines indicate the average of 7 normal rabbits; light circles with dotted lines that of 4 doubly suprarenalectomized; triangles with dash and dotted lines that of 11 doubly splanchnicotomized.

the average blood sugar fluctuation of 7 normal rabbits, light circles with dotted lines the mean of 4 doubly suprarenalectomized, and lastly triangles with dash and dotted lines that of 11 double splanchnicotomized. The initial value has been taken as 100 .

\section{SUMmaRY.}

Potassium cyanide was hypodermically injected in the dose of 2.5 mgrms. per kilo of body weight into rabbits, normal, doubly suprarenalectomized and doubly splanchnicotomized as well.

A hyperglycaemia of a moderate strength occurred in normal rabbits constantly, whereas some experimentalists using a similar dosage have failed to elicit such a constant outcome.

Double suprarenalectomy did not largely interfere with the magnitude of hyperglycaemia due to cyanide, while double splanchnicotomy was capable of very conspicuously abolishing the effect of cyanide upon the blood sugar concentration.

It is thus elucidated that the hyperglycaemia in the cyanide intoxication is to a very large extent of the central origin, but existence of the suprarenal glands has only a small share in eliciting this hyperglycaemia. 

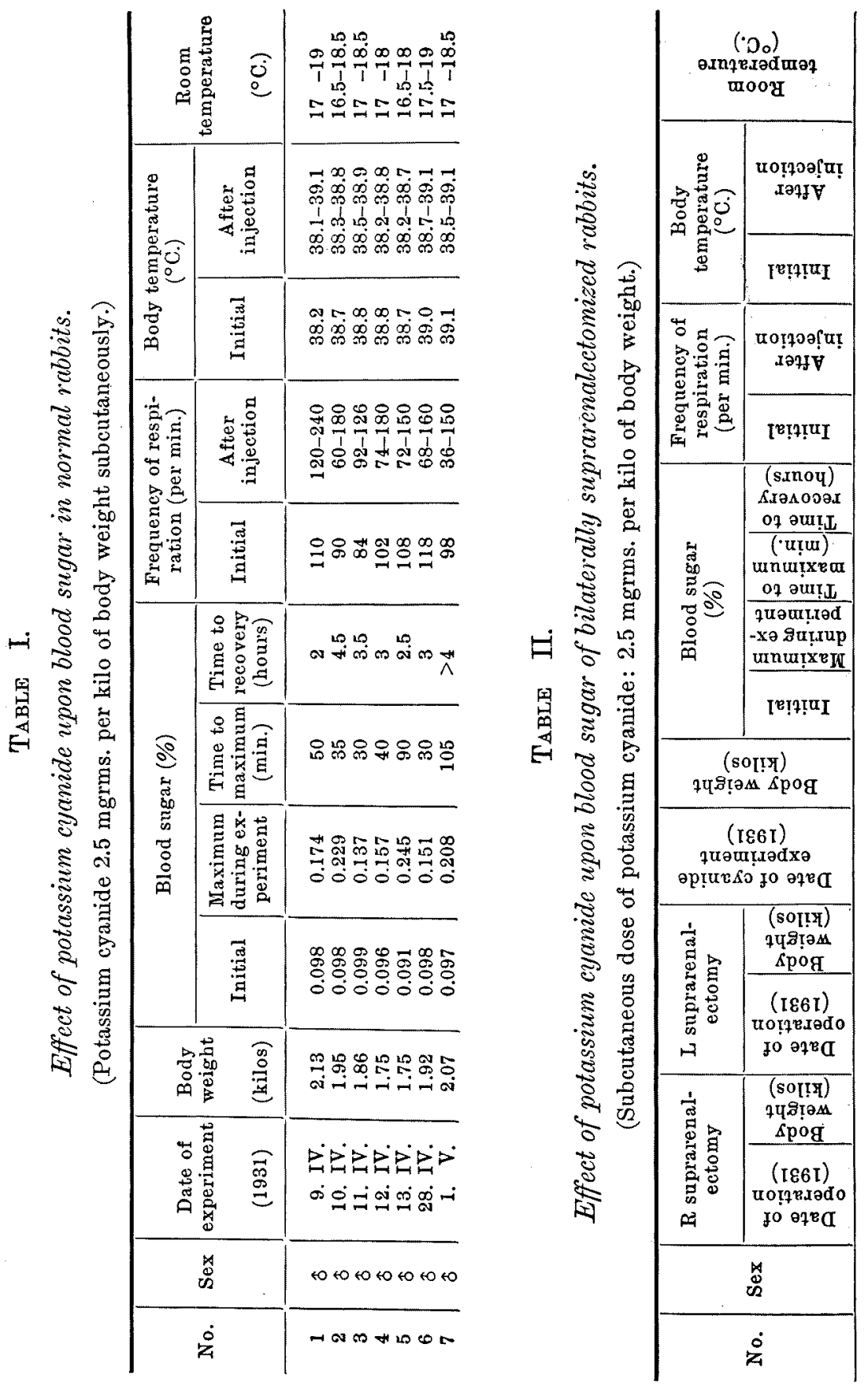


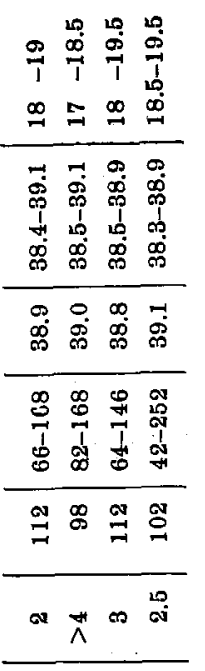

임애

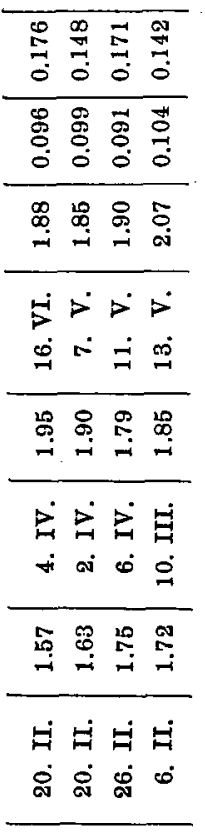

to to to so

$\infty \circ @=$

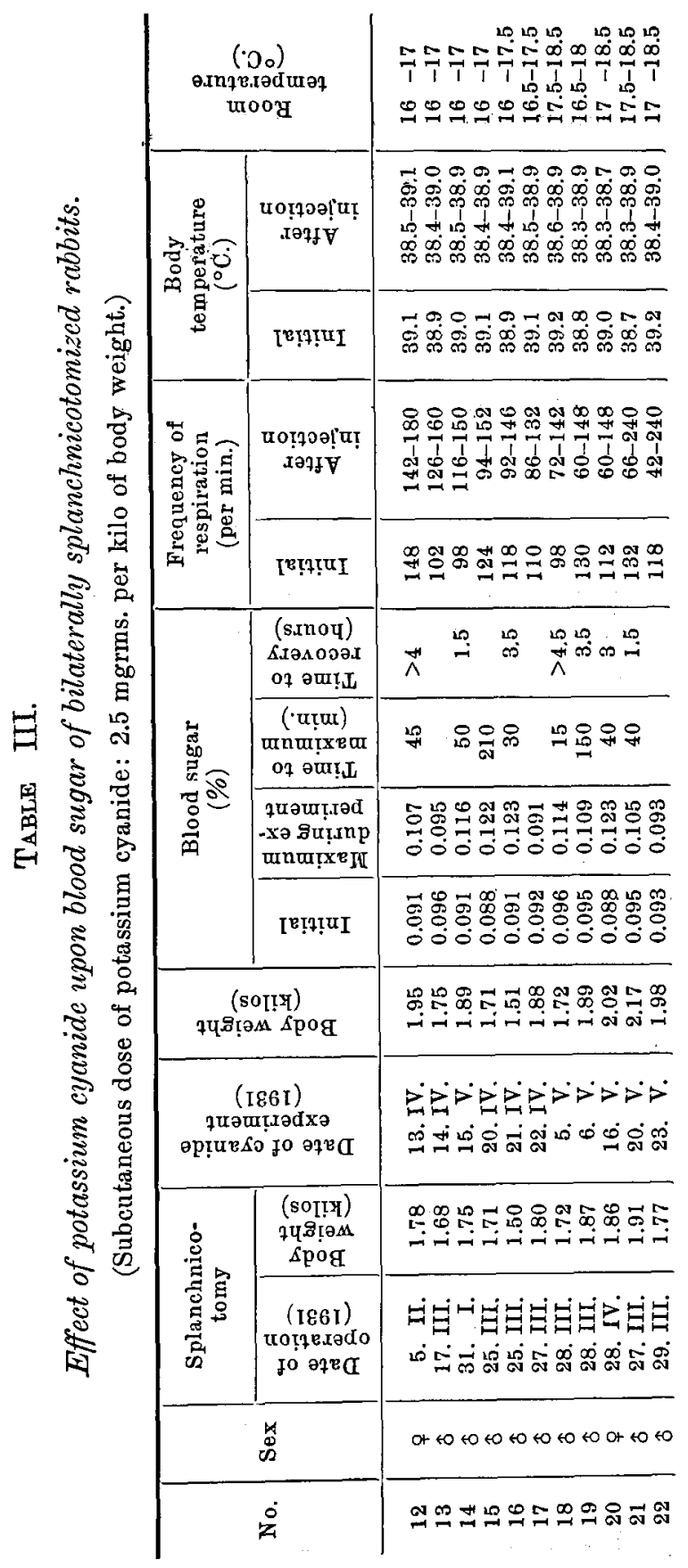

